\title{
From flood risk to indirect flood impact: evaluation of street network performance for effective management, response and repair
}

\author{
J. Gil \& P. Steinbach \\ Space Syntax Limited, UK
}

\begin{abstract}
Current flood risk assessment and decision support tools, the UK Planning Policy Statement 25 and the UK Environment Agency (EA) flood maps, focus on the areas directly affected by flooding; however they do not address the indirect consequences of flooding on the existing street network. Research has been done in transport network reliability and resilience to disasters but little application exists to the floods scenario. In this paper we introduce a methodology developed at Space Syntax Limited to analyse and visualise the wider impact of flooding on the urban street network, measuring its performance in order to respond to the situation more effectively. Starting from a hypothetical scenario of floods in London affecting the areas within the highest risk flood Zone 3 as defined by the EA, we use a spatial model of London up to the M25 circular motorway and run network analysis algorithms before and after the flooding. Using a GIS we quantify the extent to which flooding affects the global structure of the city and the spatial accessibility of town centres. The analysis also provides indicators of traffic level distributions to evaluate the performance of the strategic transport network revealing a dependency on the M25 in the flooded scenario for longer trips across London, suggesting congestion levels beyond its capacity. With this work we demonstrate that space syntax network analysis provides objective indicators to demonstrate the indirect impacts of flooding on urban street networks which can be used by relevant authorities to support a future vision and their investment decisions concerning preventative strategies, disaster management and repair.
\end{abstract}

Keywords: climate change, flooding, urban street networks, spatial analysis, space syntax, GIS, mapping, impact assessment, scenario testing, adaptation strategy. 


\section{Introduction}

In the current scenario of climate change and extreme weather it is reported that there is an increased risk of flooding, both from flash floods and sea level rise (Hulme et al. [1]). As a consequence the government has organisations like the Environment Agency, Defra or UK Climate Impacts Programme (UKCIP) addressing these issues and is funding research programmes on sustainable development to minimise the impact on the environment and respond to the consequences of climate change.

\subsection{Climate change and floods research}

The research on initial floods as a consequence of climate change has focused on mitigation technologies and risk assessment methodologies but now there is a requirement to focus on adaptation technologies and on sharing knowledge across academic and non-academic disciplines (Shaw et al. [2]).

In accepting that climate change is inevitable the RIBA's think tank "Building Futures" gathered researchers to discuss the design challenges ahead, presenting visions of a future of coexistence with water and making recommendations for strategic thinking. "Address the need for a visionary strategic plan for future flood risk, addressing rising water levels and future London growth." (Willars [3]).

\subsection{UK policy on flooding}

The UK Planning Policy Statement 25 (PPS25) (PPS [4]) describes the causes of flood risk and introduces rules and measures to manage and reduce this risk. Furthermore the UK Environment Agency (EA) is responsible for the modelling of flood zones and an online mapping facility to assess flood risk in urban, rural and coastal areas (EA [5]) which indicates if a property is within a high risk flood zone. Interested individuals have the chance to see if their property is affected by floods for insurance, investment or safety reasons.

As a result of PPS25 tools (SEEDA et al. [6], UKCIP [7]) and consultancy services (Ambiental [8]) have been created to support the planning process, assess the flood risk of new developments and support individuals to prevent flood damage. These flood risk assessment tools focus on the areas within or directly adjacent to flood risk zones and on new urban developments.

\subsection{Flooding in the media}

Climate change and flooding disasters have been extensively covered by the media in an amplification of the above concerns (Channel 4 [9]). In response we are presented with dramatic images of flooded areas with calculations of damage to property and disruption to transport networks when train lines or roads are cut by water. Once again the focus is on the visible and direct damage to property. 
In this paper we look at floods in urban environments and propose a methodology to study the indirect impact to the urban street network, i.e. the impact on areas not within or directly adjacent to the flood zones. Our focus is on understanding the consequences to the existing urban structure with a view to a longer term strategy and adaptation vision. How can we understand the wider impact of flooding on the urban street network, respond to the situation, repair it or adapt to it more effectively?

Firstly we present the background on street network analysis; we then describe the proposed methodology applied to a scenario of floods in London, providing a summary of the results. Next we discuss how these results can be used to evaluate the impact on the road transport network and the activity of local centres. Finally we propose how this methodology can be further developed.

\section{Considering street network analysis}

Current flood risk assessment tools are based on maps that show 'where it happens' and if a site is not directly affected everything seems fine. What is not apparent are the indirect consequences of flooding as a property or street that is not within or adjacent to a flood risk zone it can suffer some sort of impact become isolated to different degrees:

- An island without land access to the surroundings

- A peninsula with a single connection which will become a critical route for emergency access

- A peripheral area that is more difficult to get to than before

- Or this site might become an accessible area playing a more central role than before.

It is known that floods have a serious impact on the transport network (Arkell and Darch [10]) and as research on transport network reliability and resilience to disasters demonstrates a disruption to particular nodes of that network can have different degrees of disruption throughout (Sakakibara et al. [11]). In the specific case of flooding, the disruption can affect large continuous areas of the urban street network and is such that maps, GIS information and GPS systems become incorrect and useless (Capaccio and Ellis [12]). For this reason we need to move to street network analysis methods.

Street network analysis using space syntax methodologies (Hillier and Hanson [13]) is able to provide network measures of connectivity, accessibility (closeness) and path overlap (betweenness) that have been shown to correlate with pedestrian movement as well as cyclist, car and underground (Hillier and Iida [14], Raford et al. [15], McCahill and Garrick [16], Chiaradia et al. [17, 18]). Furthermore it is suitable to evaluate urban activity (Hillier [19]) and test scenarios where dramatic changes to the street configuration introduce functional changes over time, as in the case of the fall of the Berlin wall (Desyllas [20]).

We propose to apply space syntax street network analysis methodologies to a floods scenario to evaluate performance changes to the urban structure and activities. 


\section{Methodology}

This paper introduces a methodology developed at Space Syntax Limited to analyse and visualise the indirect impact of flooding on the urban street network and measure its performance, demonstrating the consequences to local and global spatial accessibility and levels of flow from path overlap.

\subsection{The scenario}

We model a disaster scenario of floods in London where as a consequence of sea level rise and the failure of the Thames barrier all the areas covered by the highest risk flood Zone 3, defined by the Environment Agency, are affected. This is a dramatic scenario useful for a visioning exercise to show a large scale of change to central London as presented in the movie 'Flood' (Mitchell [21]), but taking into account realistic data and concerns (GLA [22-24]).

Such a disaster would have a short term impact on the performance of the network but also long term consequences after the restoration of the water levels as in the case of New Orleans, and as such is also suitable to discuss longer term impacts and the socio-economic change of the city.

\subsection{Preparation of the spatial models}

The process starts by taking an existing spatial model of London (A) up to the M25 circular motorway constructed according to the space syntax principles defined by Hillier and Hanson [13] with the longest and fewest lines covering the public space.

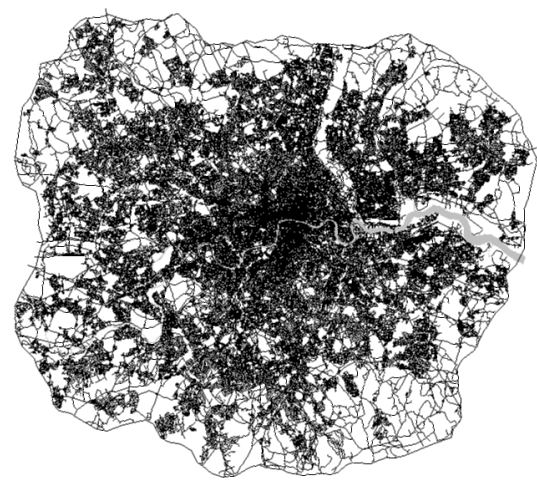

(A)

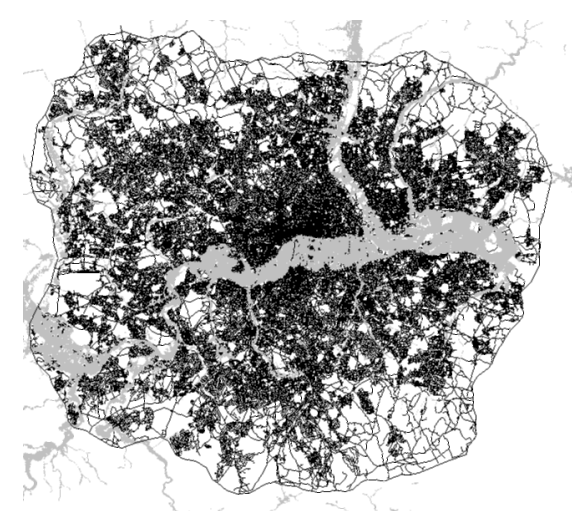

(B)

Figure 1: $\quad$ Spatial model of London before (A) and after the floods (B).

This model is then brought into the MapInfo Professional GIS and we overlay the flood Zone maps. We proceed to create a new model that represents the flooded scenario (B) by performing a series of operations with support from tools from the Confeego plug-in (Gil et al. [25]): 
1. Select all the streets that are intersecting by the flood Zone 3

2. Eliminate from this subset all the streets that are entirely within flood Zone 3

3. Remove the portions of streets that are partially flooded

4. Eliminate any resulting street segments that are unconnected from the rest of the network

The two spatial models, before and after the floods (fig. 1), are compared in table 1 in a direct statistical assessment of the flood's impact on the city structure without the use of street network analysis (Batty [26]).

The most striking figure in model $\mathrm{B}$ is the increase in absolute number of culde-sacs despite the decrease in streets segments. Also in model B islands unconnected from the main network appear. The drop in total connectivity is a direct result of a smaller system with fewer segments.

We could look into these statistics in further detail however our purpose is to investigate the indirect impacts on the city structure with street network analysis.

Table 1: $\quad$ Comparison of the two spatial models.

\begin{tabular}{|l|l|l|l|}
\hline & Model A & Model B & Difference(B-A) \\
\hline Street segments count & 287,292 & 248,925 & $-13,4 \%$ \\
\hline Total street length & $20,343 \mathrm{~km}$ & $17,883 \mathrm{~km}$ & $-12,1 \%$ \\
\hline Average street length & $70,8 \mathrm{~m}$ & $71,8 \mathrm{~m}$ & $+1.4 \%$ \\
\hline Total Connectivity & 358,764 & 307,020 & $-14 \%$ \\
\hline Average connectivity & 3.56 & 3.38 & $-5 \%$ \\
\hline Count of cul-de-sacs & 31,434 & 34,264 & $+9 \%$ \\
\hline$\%$ street length cul-de-sacs & $11 \%$ & $14 \%$ & $+3 \%$ \\
\hline$\%$ streets in islands & $0 \%$ & $5 \%$ & $+5 \%$ \\
\hline$\%$ street length islands & $0 \%$ & $4 \%$ & $+4 \%$ \\
\hline
\end{tabular}

\subsection{Street network analysis of the spatial models}

We now convert models A and B into street networks within the GIS where the lines representing the public space stand for the nodes and the intersections between these lines are the links (Jiang and Claramunt [27]). We then run the space syntax analysis algorithms using Confeego (Space Syntax [28]) and Depthmap (Turner [29]) to evaluate network performance in terms of spatial accessibility (closeness) and path overlap (betweenness) at global and local radii. The global radius considers trips between any origin/destination pair in the network whatever the metric distance between the nodes, while the local radius restricts trips to those smaller or equal to 800 metres, which corresponds to more local behaviour. The results are gathered in the GIS for statistical analysis and mapping.

\section{Summary of the results}

We present a brief summary of the street network analysis results, showing maps that reveal the urban morphology of models $\mathrm{A}$ and $\mathrm{B}$ and the impact on 
accessibility - how close a street is to the others in the network - and on path overlap - how frequently it is chosen for trips across the network (Hillier [30]).

\subsection{Urban morphology}

To present the urban morphology of each model we display maps with the top $10 \%$ (black) and bottom 10\% (darker grey) streets in terms of global (fig. 2, 3) and local (fig. 4) accessibility and path overlap.
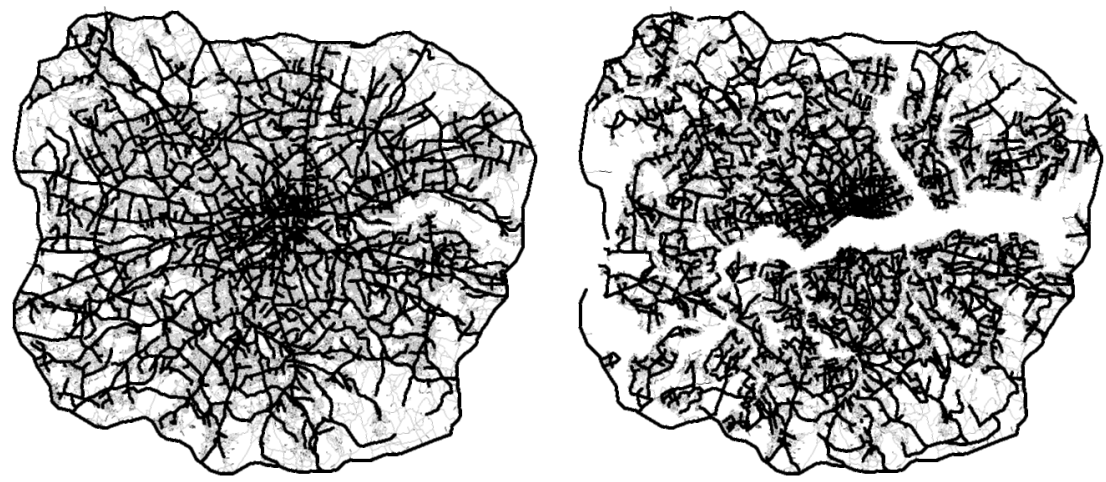

Figure 2: $\quad$ Global path overlap (model A and B).
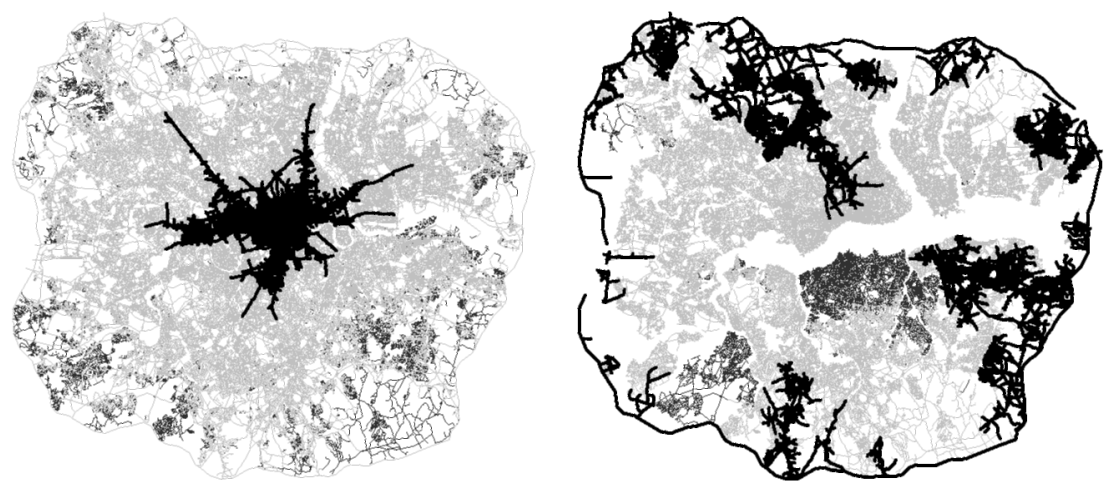

Figure 3: $\quad$ Global accessibility (model A and B).

In model B the main change is the reversal in global accessibility (fig. 3), where the areas closest to the overall population are on the periphery, as most direct connections to the current centre are cut. In terms of global path overlap (fig. 2) the major road network that is clearly defined in model A becomes in model B fragmented and dispersed. Local path overlap (fig. 4) doesn't display much change in the streets further away from the flooded area but must be looked at in detail at another scale. 

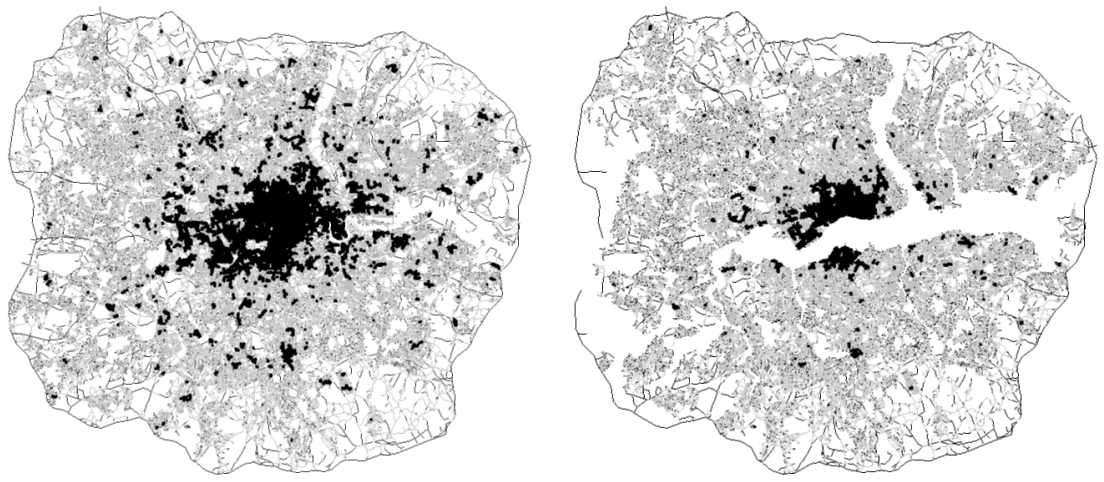

Figure 4: $\quad$ Local path overlap (model A and B).

\subsection{Impact maps}

The impact maps represent the difference in scaled values between models A and $\mathrm{B}$, where the values are positive where model B has an increase (black) and negative where model $\mathrm{B}$ has a decrease (dark grey) in relation to model A.
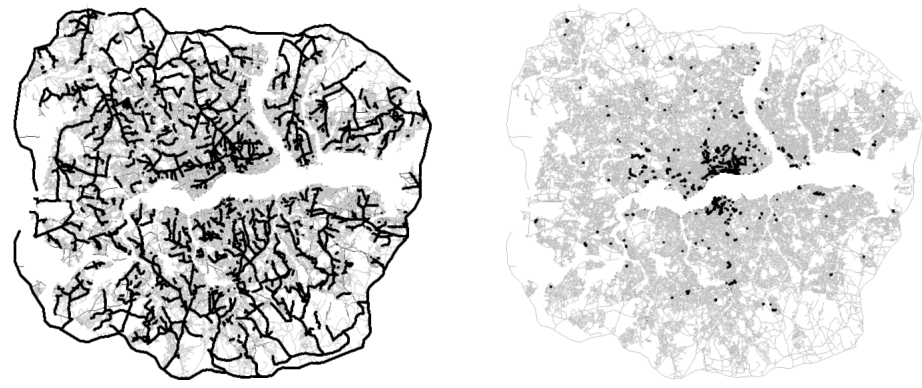

Figure 5: $\quad$ Path overlap impact (global and local).
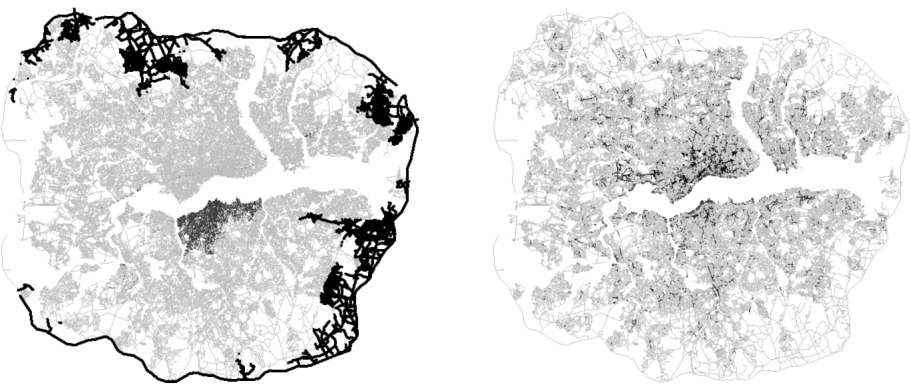

Figure 6: Accessibility impact (global and local). 


\section{What can these results tell us?}

The previous results can provide indication of the extent to which flooding affects the performance of the strategic transport network, defined by the street segments that compose TfL's M25 and TLRN (tab. 2), or the spatial accessibility of selected town centres (tab. 3), defined by the street segments within $800 \mathrm{~m}$ of TCPA's local centres. The result is a calculation of the percent change in ranking of path overlap and accessibility of the street segments before and after the floods.

Table 2: $\quad$ Evaluation of the strategic road network.

\begin{tabular}{|l|l|l|l|l|}
\hline & $\begin{array}{l}\text { Global Path } \\
\text { Overlap }\end{array}$ & $\begin{array}{l}\text { Local Path } \\
\text { Overlap }\end{array}$ & $\begin{array}{l}\text { Global } \\
\text { Accessibility }\end{array}$ & $\begin{array}{l}\text { Local } \\
\text { Accessibility }\end{array}$ \\
\hline M25 & $+1030 \%$ & $+29 \%$ & $+100 \%$ & $+5.4 \%$ \\
\hline TLRN & $-83 \%$ & $-6 \%$ & $-34 \%$ & $-3.8 \%$ \\
\hline
\end{tabular}

Table 3: $\quad$ Selected town centre performance.

\begin{tabular}{|l|l|l|l|l|}
\hline & $\begin{array}{l}\text { Global Path } \\
\text { Overlap }\end{array}$ & $\begin{array}{l}\text { Local Path } \\
\text { Overlap }\end{array}$ & $\begin{array}{l}\text { Global } \\
\text { Accessibility }\end{array}$ & $\begin{array}{l}\text { Local } \\
\text { Accessibility }\end{array}$ \\
\hline Archway & $+1596 \%$ & $+1 \%$ & $+12.8 \%$ & $+2.7 \%$ \\
\hline Brixton & $-75 \%$ & $-4 \%$ & $-75 \%$ & $-1.4 \%$ \\
\hline Leadenhall Mkt & $-91 \%$ & $-2.3 \%$ & $-31 \%$ & $-3 \%$ \\
\hline N Finchley & $+2355 \%$ & $-1.4 \%$ & $+65 \%$ & $+0.4 \%$ \\
\hline West End & $-87 \%$ & $-8 \%$ & $-26 \%$ & $-3 \%$ \\
\hline
\end{tabular}

These percentages reflect the dramatic dependency on the M25, the failure of the TLRN mainly on circular roads, the decrease in global values of South London, the shift of global accessibility from the West End to the North, a decrease of global values in the City and the increase in path overlap of the areas leading to the M25. Overall local indicators don't change considerably.

\subsection{Further work}

This methodology opens possibilities for further research, in particular when it comes to more localised features, like the best location for emergency services or identifying the most direct routes, as the model has a street segment level of detail unlike other transport or land use models.

The street network model's flexibility and calculation time takes us to the other main application: the testing of different scenarios. We can create new scenarios and apply the complete methodology, for example with the Thames barrier resisting the floods or without the M25 considering it fails to cope with the high levels of demand. Furthermore we can use the flooded future scenario as a 'Business as usual' model where we can experiment with the addition of new links across the flooded areas in the form of bridges or boat crossings, in an attempt test how particular solutions would to restore the city to its previous morphological and functional structure. 


\section{Conclusion}

With this work we identify a gap in current policy and research where the focus is on flood risk and the directly affected areas. We then show the potential of street network analysis to provide objective indicators of the indirect impacts of flooding on urban street networks in areas not within or directly adjacent to flood risk areas. The proposed methodology extracts objective properties of the urban street network, which is then analysed statistically and mapped visually. These objective properties become useful indicators of indirect impact on transport network performance and socio-economic conditions in an urban environment. These network models can be used as a baseline on which to test different interventions and to support investment decisions concerning preventative strategies, disaster management and repair.

This working model complements existing planning policy with a strategic tool that can support the relevant authorities in exploring longer term strategic plans towards a more sustainable vision of the future.

\section{References}

[1] Hulme, M., et al., Climate Change Scenarios for the United Kingdom: The UKCIP02 Scientific Report, Tyndall Centre for Climate Change Research, University of East Anglia, Norwich, UK, 2002

[2] Shaw, R., Colley, M., and Connell, R., Climate change adaptation by design: a guide for sustainable communities. TCPA, London, 2007

[3] Willars, E. (ed.), Living with water: visions of a flooded future, Building Futures, UK, 2007

[4] Planning Policy Statements: PPS1 (Delivering sustainable development) and PPS25 (Development and flood risk). Online www.communities.gov.uk

[5] UK Environment Agency, Flood Map: What's in your backyard? UK, 2008. Online http://maps.environment-agency.gov.uk/wiyby/mapController

[6] SEEDA, WWF \& BRE, Sustainability Checklist South East, UK, 2008. Online http://southeast.sustainability-checklist.co.uk/

[7] UK Climate Impacts Programme (UKCIP), Adaptation Wizard, UK, 2008. Online http://www.ukcip.org.uk/

[8] Ambiental, Flood Risk Assessment, UK, 2008. Online http://flood-riskassessment.com/

[9] Channel 4, Dispatches: Britain under Water, 60 minutes, UK, 2007

[10] Arkell B. \& Darch G., Impact of climate change on London's transport network, In: Proceedings of the Institution of Civil Engineers, Municipal Engineer 159, December 2006 Issue ME4, Pages 231-237, 2006

[11] Sakakibara1 H., Kajitani, Y. \& Okada, N., Road Network Robustness for Avoiding Functional Isolation in Disasters, In: Journal of Transportation Engineering, September-October 2004, pp. 680-687, 2004

[12] Capaccio, R. \& Ellis, J., A Proposal to Enhance Emergency Routing for Hospital and Critical Care Facilities, In: Directions Magazine, 2005. Online: http://www.directionsmag.com/article.php?article_id=1983\&trv=1 
[13] Hillier, B. \& Hanson, J., The Social Logic of Space, Cambridge University Press, UK, 1989

[14] Hillier, B. \& Iida, S., Network and psychological effects in urban movement, In: Proceedings of Spatial Information Theory: International Conference, COSIT 2005, Cohn, A.G. and Mark, D.M. (eds). New York, USA, 2005

[15] Raford, N., Chiaradia, A. \& Gil, J., Critical Mass: Emergent cyclist route choice in central London, In: 5th International Space Syntax Symposium, Technical University Delft, Netherlands, 2005

[16] McCahill, C. \& Garrick, N., Applicability of Space Syntax to Bicycle Facility Planning, In: Transportation Research Board $87^{\text {th }}$ Annual Meeting Compendium of Papers, \#08-2653, Washington, USA, 2008

[17] Chiaradia, A., Emergent Route Choice Behaviour, Motorway and Trunk Road Network: the Nantes conurbation, In: 6th International Space Syntax Symposium, Istanbul Technical University, Turkey, 2007

[18] Chiaradia, A., Moreau, E. Raford, N. Configurational Exploration of Public Transport Movement Networks: Case Study, the London Underground, In: 5th International Space Syntax Symposium, Technical University Delft, Netherlands, 2005

[19] Hillier, B., Centrality as a process: accounting for attraction inequalities in deformed grids, In: Urban Design International, 4 (3), pp. 107-127, 1999

[20] Desyllas, J., The relationship between urban street configuration and office rent patterns in Berlin, $\mathrm{PhD}$ Thesis, University College London, UK, 2000

[21] Mitchell, T. (director), Flood, 110 minutes, Lionsgate UK, 2007

[22] Greater London Authority (GLA), Flooding in London: A London Assembly Scrutiny Report, London, UK, 2002

[23] Greater London Authority (GLA), London's Warming: The Impacts of Climate Change on London, London, UK, 2002

[24] Greater London Authority (GLA), London Under Threat: Flood risk in the Thames Gateway, London, UK, 2005

[25] Gil, J., Stutz, C. \& Chiaradia, A., Confeego: Tool set for spatial configuration studies, In: Proceedings of 'New developments in Space Syntax software', editor A. Turner, Istanbul Technical University pp. 1522, Turkey, 2007

[26] Batty, M., The Size, Scale and Shape of Cities, In: Science Vol. 319. no. 5864, pp. $769-771,2008$

[27] Jiang, B. \& Claramunt C., Integration of Space Syntax into GIS: New Perspectives for Urban Morphology, In: Transactions in GIS (6), Blackwell Publishers, pp. 295-309, 2002

[28] Space Syntax Limited, Confeego v1.0, UK, 2007. Online http://www.spacesyntax.org/software/newtools.asp

[29] Turner, A., Depthmap 6.08.24r, University College London, UK, 2007 Online http://www.vr.ucl.ac.uk/depthmap/

[30] Hillier, B., Space is the Machine: a configurational theory of architecture, Space Syntax, London, UK, 2007 